\title{
Variation of GPS Precipitable Water over the Qinghai-Tibet Plateau: Possible Teleconnection Triggering Rainfall over the Yangtze River Valley
}

\author{
Gui-Rong $\mathrm{Xu}^{1, *}$, Chun-Guang Cui ${ }^{1}$, Wu-Jie Li ${ }^{1,2}$, Wen Zhang ${ }^{2}$, and Guang-Liu Feng ${ }^{1}$ \\ ${ }^{1}$ Institute of Heavy Rain, China Meteorological Administration, Wuhan, China \\ ${ }^{2}$ Wuhan Central Meteorological Observatory, Wuhan, China
}

Received 11 January 2009, accepted 9 September 2010

\begin{abstract}
GPS technologies show many capabilities for monitoring atmospheric water vapor. This study uses GPS data from the Japan International Co-operation Agency (JICA) and Hubei GPS network to monitor precipitable water (PW) over the Qinghai-Tibet Plateau (QTP) and over the middle Yangtze River Valley (YRV). The results show that the southern QTP is wetter than the central area due to the barring effect of the Plateau on the monsoon. PW is higher in summer than other months over either the QTP or the middle YRV. The diurnal variation of PW over the QTP is more complex than that of the middle YRV with fluctuations occurring during the whole day due to the unique topography. The minimum PW over both the QTP and the middle YRV appears in the morning; however, the peak over the QTP occurs at night while the peak over the middle YRV occurs in the early afternoon. Furthermore, PW over the QTP, especially its southern and eastern edges, are positively correlated with PW over the middle YRV. This may imply that the southern and eastern Plateaus are key regions transporting atmospheric vapor to the middle YRV. Our results indicate the possibility of finding early warning signals resulting from the intensification of the QTP atmospheric vapor leading to heavy rainfall events over the middle YRV.
\end{abstract}

Key words: Ground-based GPS, Precipitable water, Qinghai-Tibet Plateau, Yangtze River Valley

Citation: Xu, G. R., C. G. Cui, W. J. Li, W. Zhang, and G. L. Feng, 2011: Variation of GPS precipitable water over the Qinghai-Tibet Plateau: Possible teleconnection triggering rainfall over the Yangtze River Valley. Terr. Atmos. Ocean. Sci., 22, 195-202, doi: 10.3319/TAO.2010.09.09.01(TibXS)

\section{INTRODUCTION}

The Qinghai-Tibet Plateau (QTP) is the largest and highest plateau in the world: its dynamic and thermal effects play an important role in the atmospheric general circulation patterns (Li 2002; Qian 2004) as well as the weather and climate of China (Xu and Chen 2006). Severe rain storms and floods in east China are mostly induced by the QTP vortex eastward movement (Yu et al. 2007). According to Xu et al. (2002), the QTP is an important transfer platform on the western edge of the forming Meiyu rains in Yangtze River Valley (YRV) over east China during summer. The interaction between the topographic effect of QTP and the monsoon water vapor flow at the southern edge initiates strong water vapor flow from the QTP to the YRV. Regional simulations show that mesoscale topographic features play an important role in generating and enhancing the mesoscale disturbances over the QTP; these disturbances can increase

\footnotetext{
* Corresponding author

E-mail:grxu2007@gmail.com
}

the surface sensible heat flux over the QTP and propagate eastward to enhance the convection and precipitation in the YRV (Shi et al. 2008). Thus more information on moisture, temperature and pressure over the QTP and its surrounding areas is therefore important for forecasting precipitation over downstream areas (Peng et al. 2009). However, few observational data are available in the QTP because of the complex terrain and difficult weather conditions.

Recently, the development of GPS technology has provided the possibility to obtain detailed atmospheric data. Precipitable water (PW) can be obtained from ground-based GPS observations using the approach of Bevis et al. (1994) based on the linear relationship between the zenith wet delay (ZWD) and PW. GPS observations can be available automatically at high temporal resolution regardless of weather conditions. Using the GPS water vapor observation network of the Japan International Co-operation Agency (JICA), Xu et al. (2008) discussed the atmospheric water vapor data collected over the QTP and the surrounding area. 
In this study, we examine the variation in PW over the QTP using data from GPS water vapor observation network of the JICA during 2008, and also explore the relationship between PW in the QTP and the middle YRV.

\section{DATA AND METHODOLOGY}

The GPS data for the QTP are obtained from the JICA GPS water vapor observation network (Xu et al. 2008), and data for the middle YRV are from the Hubei GPS water vapor observation network managed by the Institute of Heavy Rain (IHR), China Meteorological Administration (CMA). Nine GPS stations in the QTP and twelve in Hubei province are used in this study. The data for the QTP covers the period of January through December 2008, except for October. For a given station in the QTP, the data is occasionally discontinuous due to power outages, communication interruptions, or other equipment problems. Because the Hubei GPS network is set up after March in 2008, the data in Hubei covers only April through December. The GPS data temporal resolution is hourly. Figure 1 shows the distribution of the selected GPS stations, and Table 1 presents the corresponding coordinate information. Among the stations in the QTP, there are five stations (RUOE, GANZ, LITA, DEQN and BFLJ) located in the eastern edge, and others located in the southern edge (LINZ and DINR) and central area (NAQU and GAIZ), respectively. All stations in Hubei are located in the plain.

In deriving the PW from ground-based GPS observation, the zenith total delay (ZTD) is calculated with GAMIT software developed by Massachusetts Institute of Technology (MIT). Zenith hydrostatic delay (ZHD) is calculated from the model given by Elgered et al. (1991):

(a)

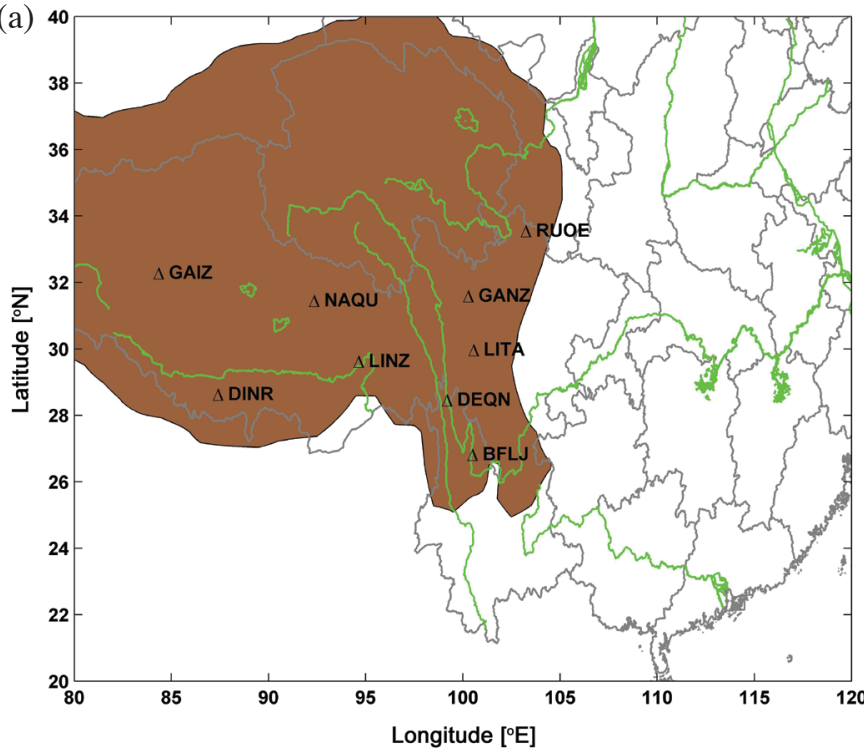

$\left\{\begin{array}{l}\mathrm{ZHD}=(2.2779 \pm 0.0024) \frac{P_{0}}{f(\Phi, H)} \\ f(\Phi, H)=(1-0.00266 \cos 2 \Phi-0.00028 H)\end{array}\right.$

where $P_{0}$ is surface pressure in $\mathrm{hPa}, \Phi$ and $H$ are the latitude and height (in $\mathrm{km}$ ) of the station, respectively. ZWD is obtained by subtracting ZHD from ZTD. Finally, PW is derived from ZWD using the following formula given by Bevis et al. (1994):

$\left\{\begin{array}{l}\mathrm{PW}=\Pi \times \mathrm{ZWD} \\ \Pi=\frac{10^{6}}{\rho R_{v}\left[\left(k_{3} / T_{m}\right)+k_{2}^{\prime}\right]}\end{array}\right.$

where $\rho$ denotes the density of liquid water, $R_{v}$ is the specific gas constant for water vapor, and $T_{m}$ represents the weighted mean temperature of the atmosphere; $T_{m}$ is defined as (Davis et al. 1985):

$T_{m}=\frac{\int\left(P_{v} / T\right) d z}{\int\left(P_{v} / T^{2}\right) d z}$

$T_{m}$ has a linear relation with the surface temperature $T_{s}$. We calculate $T_{m}$ through the following formula (Bevis et al. 1992):

$T_{m}=70.2+0.72 T_{s}$

In formula (2),

$k_{2}^{\prime}=k_{2}-m k_{1}$

(b)

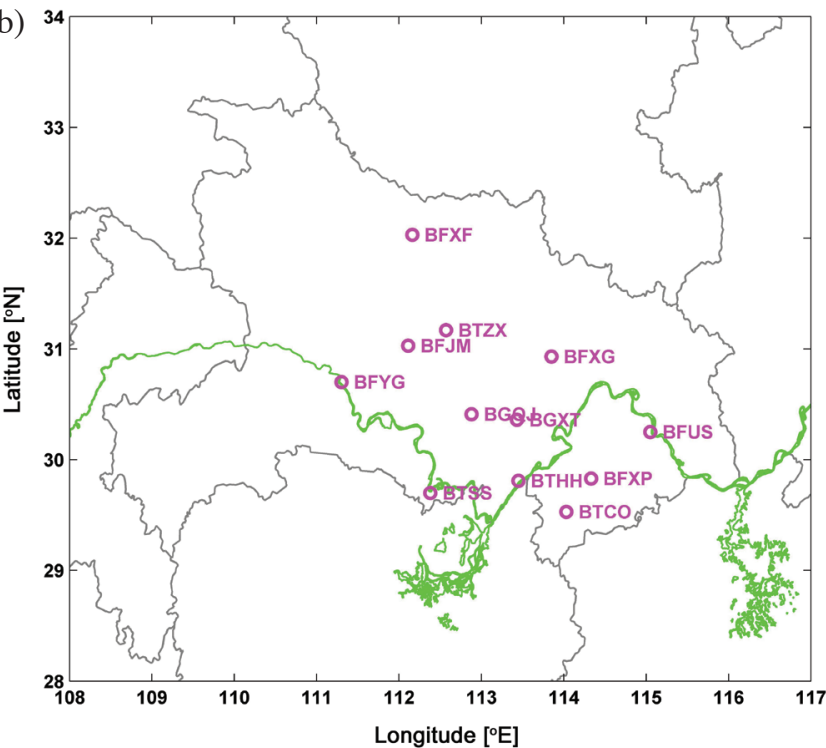

Fig. 1. Distribution of GPS stations in (a) the QTP and (b) Hubei province. The shaded area indicates stations with an altitude above $2000 \mathrm{~m}$. 
Table 1. GPS station coordinate information in the QTP and Hubei province.

\begin{tabular}{|c|c|c|c|}
\hline Station name & Longitude $\left[{ }^{\circ} \mathbf{E}\right]$ & Latitude $\left[{ }^{\circ} \mathrm{N}\right]$ & Altitude [m] \\
\hline NAQU & 92.1 & 31.5 & 4478 \\
\hline GAIZ & 84.1 & 32.3 & 4394 \\
\hline DINR & 87.1 & 28.7 & 4327 \\
\hline LITA & 100.3 & 30.0 & 3925 \\
\hline RUOE & 103.0 & 33.6 & 3418 \\
\hline GANZ & 100.0 & 31.6 & 3358 \\
\hline DEQN & 98.9 & 28.5 & 3295 \\
\hline LINZ & 94.4 & 29.6 & 2970 \\
\hline BFLJ & 100.2 & 26.8 & 2354 \\
\hline BFYG & 111.3 & 30.7 & 134 \\
\hline BFJM & 112.1 & 31.0 & 102 \\
\hline BTCO & 114.0 & 29.5 & 79 \\
\hline BFXF & 112.2 & 32.0 & 70 \\
\hline BTZX & 112.6 & 31.2 & 66 \\
\hline BFXP & 114.3 & 29.8 & 62 \\
\hline BTSS & 112.4 & 29.7 & 37 \\
\hline BGQJ & 112.9 & 30.4 & 33 \\
\hline BGXT & 113.4 & 30.4 & 30 \\
\hline BFXG & 113.9 & 30.9 & 29 \\
\hline ВTHH & 113.5 & 29.8 & 28 \\
\hline BFUS & 115.1 & 30.3 & 21 \\
\hline
\end{tabular}

and $m$ is $M_{w} / M_{d}$, the ratio of the molar masses of water vapor to the dry air. The physical constants $k_{1}, k_{2}$, and $k_{3}$ are from the widely used formula for atmospheric refractivity $N$. We adopt the values in Bevis et al. (1994): $k_{1}=77.60 \mathrm{~K}$. $\mathrm{h} \mathrm{Pa}{ }^{-1}, k_{2}=70.4 \mathrm{~K} \cdot \mathrm{h} \mathrm{Pa}{ }^{-1}, k_{3}=3.739 \times 10^{5} \mathrm{~K}^{2} \cdot \mathrm{h} \mathrm{Pa}^{-1}$.

Using the above approach, Yang et al. (2002) calculated PW of Lasa (latitude $=29.7^{\circ} \mathrm{N}$, longitude $=91^{\circ} \mathrm{E}$, altitude $=3659 \mathrm{~m}$ ) in the QTP and found the results compared with PW obtained from radiosonde data; the mean bias in PW is $0.2 \mathrm{~mm}$ with a mean square root error of $1.5 \mathrm{~mm}$, indicating the applicability of the method for the QTP.

It should be pointed out that only observations with greater than 16 hours of data for a day are used. The month- ly mean PW is calculated by averaging all samples for that month.

\section{RESULTS AND DISCUSSION \\ 3.1 Seasonal Variations of PW over the QTP}

The monthly mean PW over the Plateau stations is shown in Fig. 2. The results illustrate that PW over the QTP has obvious seasonal variation. The variation is smaller in the early part of the year, then increases in the spring and becomes greater around July or August, and then decreases after that. The seasonal variation implies a wet summer and dry winter in the QTP. This is reasonable because the warm and wet southwest monsoon is stronger in the QTP in summer and weaker during other seasons (Liang et al. 2006).

For comparison, the monthly mean PW over the Hubei stations is shown in Fig. 3. Generally, PW over Hubei shows a similar seasonal variation as PW for the QTP, which can be explained by the dominant general circulation at similar latitudes. Only slight differences are detected in PW over the Hubei stations because of their similar altitudes (see Table 1).

Figure 2 also shows an altitude dependence of the PW. As a whole, low altitude stations have a larger PW than high altitude ones since they have a larger integration range. Interestingly, sites NAQU, GAIZ and DINR have similar altitudes near $4400 \mathrm{~m}$, but PW over DINR is obviously higher than PW over NAQU and GAIZ during the summer months. Especially in July, PW over DINR is $15.5 \mathrm{~mm}$ while those over NAQU and GAIZ are about $12.0 \mathrm{~mm}$. Although the altitudes of GANZ and DEQN are nearly the same ( 3300 m), DEQN (23.2 mm in August) has an obvious larger PW than GANZ (19.9 mm in August) in the summer months. Both DINR and DEQN are located in the southern QTP, while GAIZ, NAQU and GANZ are located in the central QTP. These results indicate that the southern QTP is wetter than the central area during the summer months. The topography of the QTP is responsible for this feature. In the summer months, the southern QTP meets the warm and wet southwest monsoon, but in the central QTP the southwest monsoon becomes weak due to the barring effect of the Plateau on the monsoon, which results in wetter air in the southern QTP and drier air in the central area.

\subsection{Diurnal Variations of PW over the QTP}

Few studies have reported on diurnal variations of the atmospheric water vapor over the QTP due to the lack of data. The GPS PW used in this study provides a good opportunity to examine the variations of atmospheric water vapor over the QTP. Figure 4 shows the daily variation of PW over the QTP stations. PW is lower in the morning, and then increases until the maximum appears around midnight, 


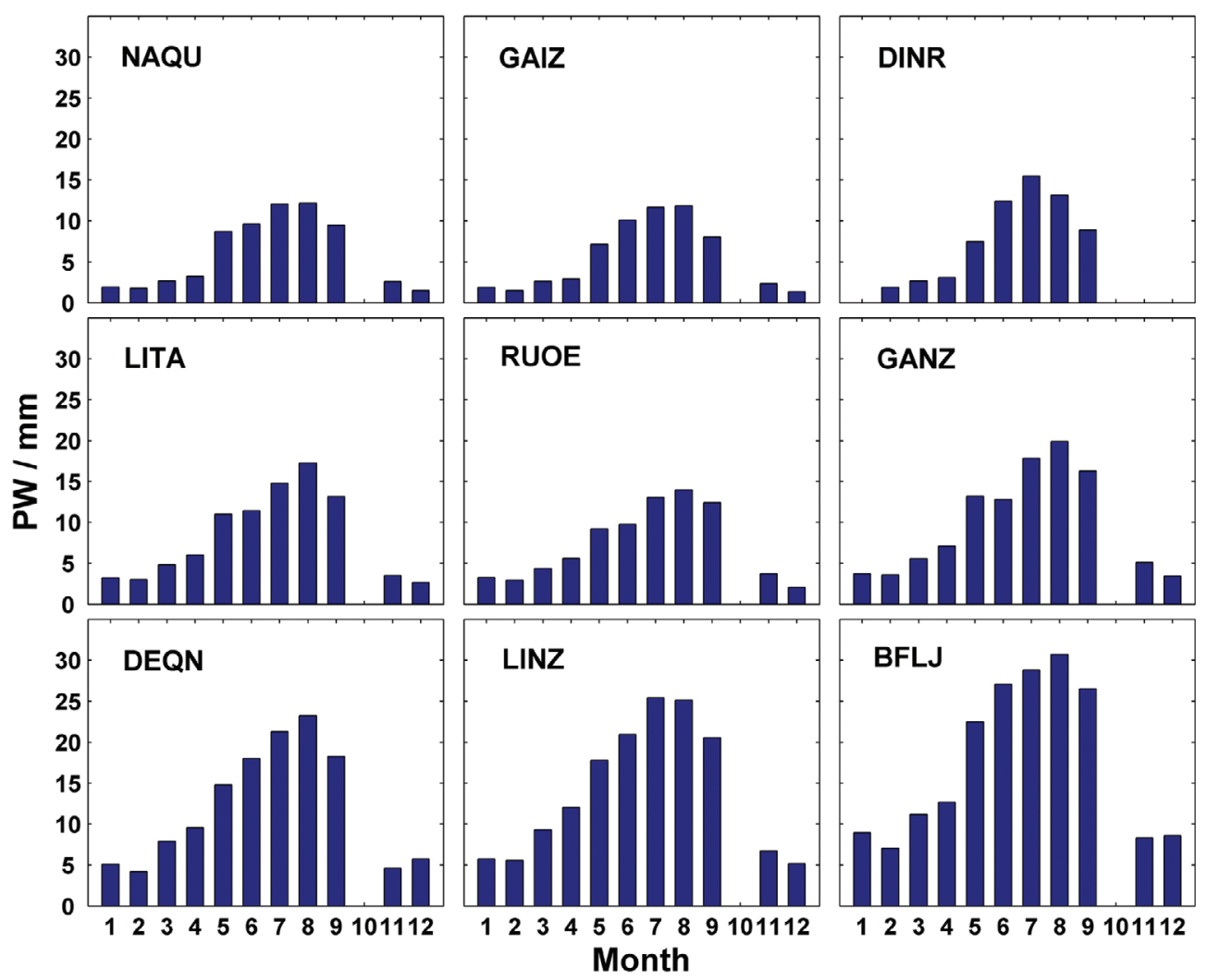

Fig. 2. Monthly mean PW over the QTP stations in 2008. No data available in October.
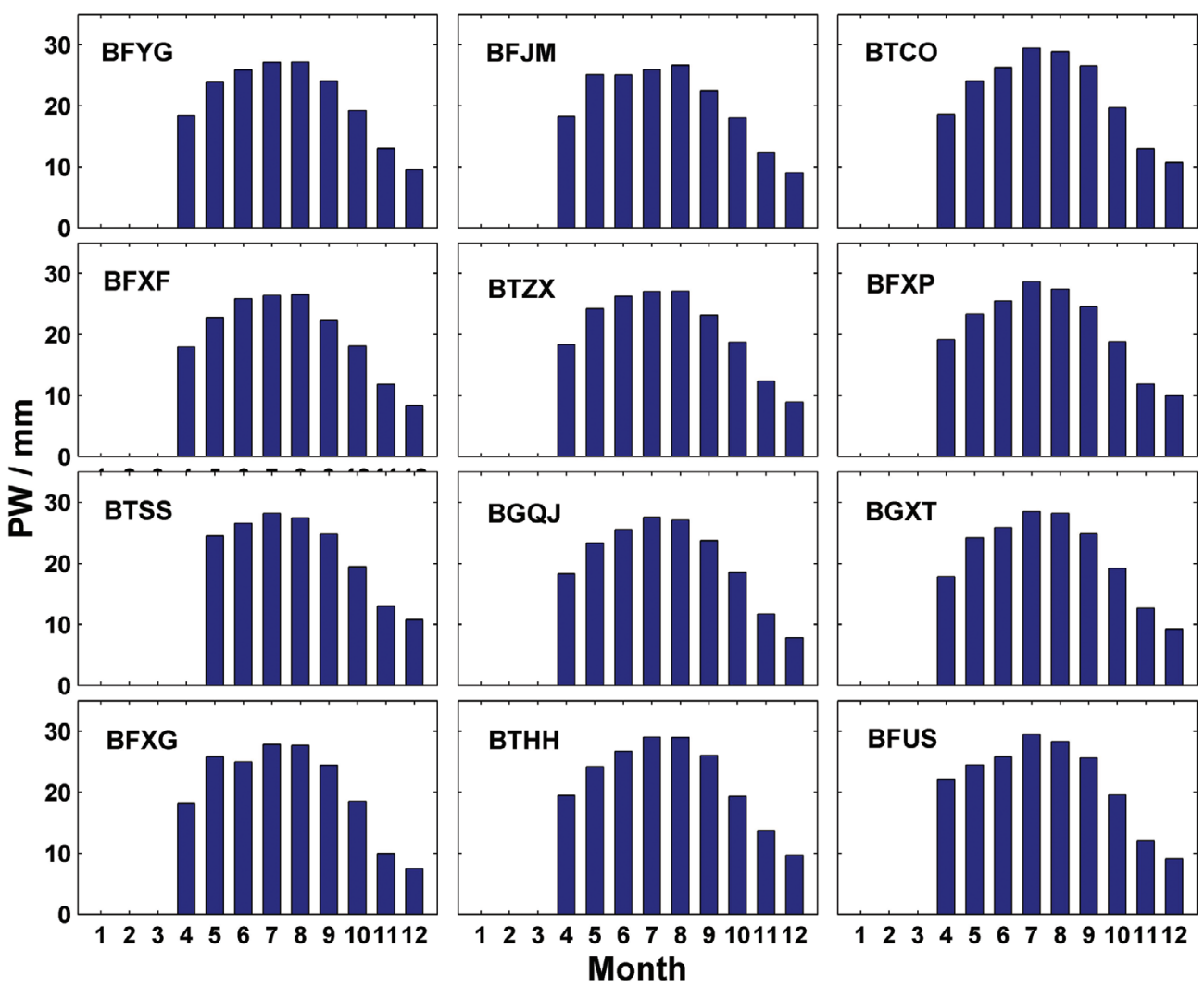

Fig. 3. Monthly mean PW over the Hubei stations in 2008. No data available during January to March. 


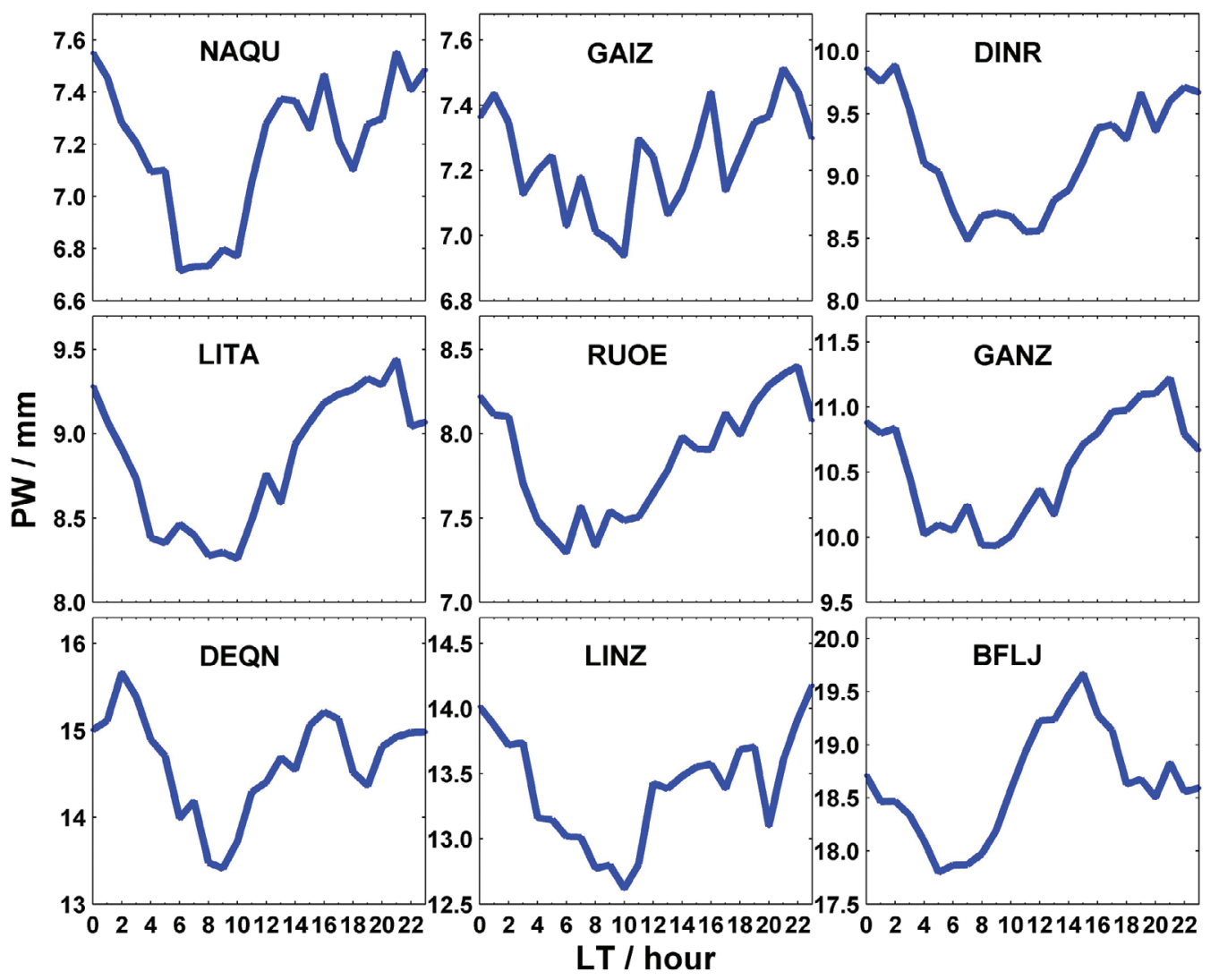

Fig. 4. Hourly mean PW over the QTP stations in 2008.

and decreases after that. Excluding BFLJ, the minimum PW $\left(\mathrm{PW}_{\min }\right)$ over the other Plateau stations appears during 0600 $1000 \mathrm{LT}$ and the maximum PW ( $\mathrm{PW}_{\max }$ ) occurs during 2100 - $0200 \mathrm{LT}$. For BFLJ, the $\mathrm{PW}_{\text {min }}$ and $\mathrm{PW}_{\text {max }}$ are at 0500 and 1500 LT, respectively. The hourly mean PW over the Hubei stations are also calculated for comparison. As shown in Fig. 5, the diurnal variation in PW is obvious and is similar for all stations, with few fluctuations during a day. The PW is low in the morning, but increases with time quickly after sunrise and approaches the maximum in the early afternoon, and then decreases following the peak. For all Hubei stations, the $\mathrm{PW}_{\min }$ occurs during $0500-0600 \mathrm{LT}$ and $\mathrm{PW}_{\max }$ during 1400 - 1500 LT. Obviously, PW $_{\min }$ over both the QTP and the middle YRV occurs in the morning; however, in the QTP except for BFLJ, the $\mathrm{PW}_{\max }$ occurs at night, while in the middle YRV it occurs in the early afternoon.

The results show that the diurnal variation in PW over the QTP is more complex than the diurnal variation over the middle YRV, which might be related to the QTP topography. In the QTP, atmospheric conditions are more instable than in the middle YRV. The fluctuations in the diurnal variation in PW over the QTP may be a representation of the variable weather in the Qinghai-Tibet Plateau. There is a striking phenomenon in the QTP, where most rainfall occurs at night (local time), which is partly due to the rela- tively larger humid and stronger convective clouds during nights over the QTP (Li 2002).

\subsection{Correlation in PW Between the QTP and the Middle YRV}

Because collecting more atmospheric data over the QTP is important and needed for forecasting precipitation in downstream areas (Peng et al. 2009), it is meaningful to examine the correlation in $\mathrm{PW}$ between these two areas. We calculate the correlation coefficients in PW between the QTP and Hubei stations during the corresponding UT period as presented in Fig. 6. The correlation coefficients for PW (marked as $r_{P W}$ ) between the QTP and Hubei stations are generally above 0.5 , with several exceptions for DINR and GAIZ. For DINR, however, there are three stations in Hubei having $r_{P W}$ less than 0.5 , which may be the influence of the data gap. Furthermore, the $r_{P W}$ for the five stations in the eastern edge of the QTP vary between $0.5873-0.7255$, and for LINZ, between $0.6379-0.8123$, both higher than $r_{P W}$ for the two stations in the central QTP (range 0.4812 - 0.6327). These results suggest a positive correlation in PW between the QTP and the middle YRV, and the positive correlation is more obvious for the southern and eastern edges of the QTP compared to the correlation for the central area. 


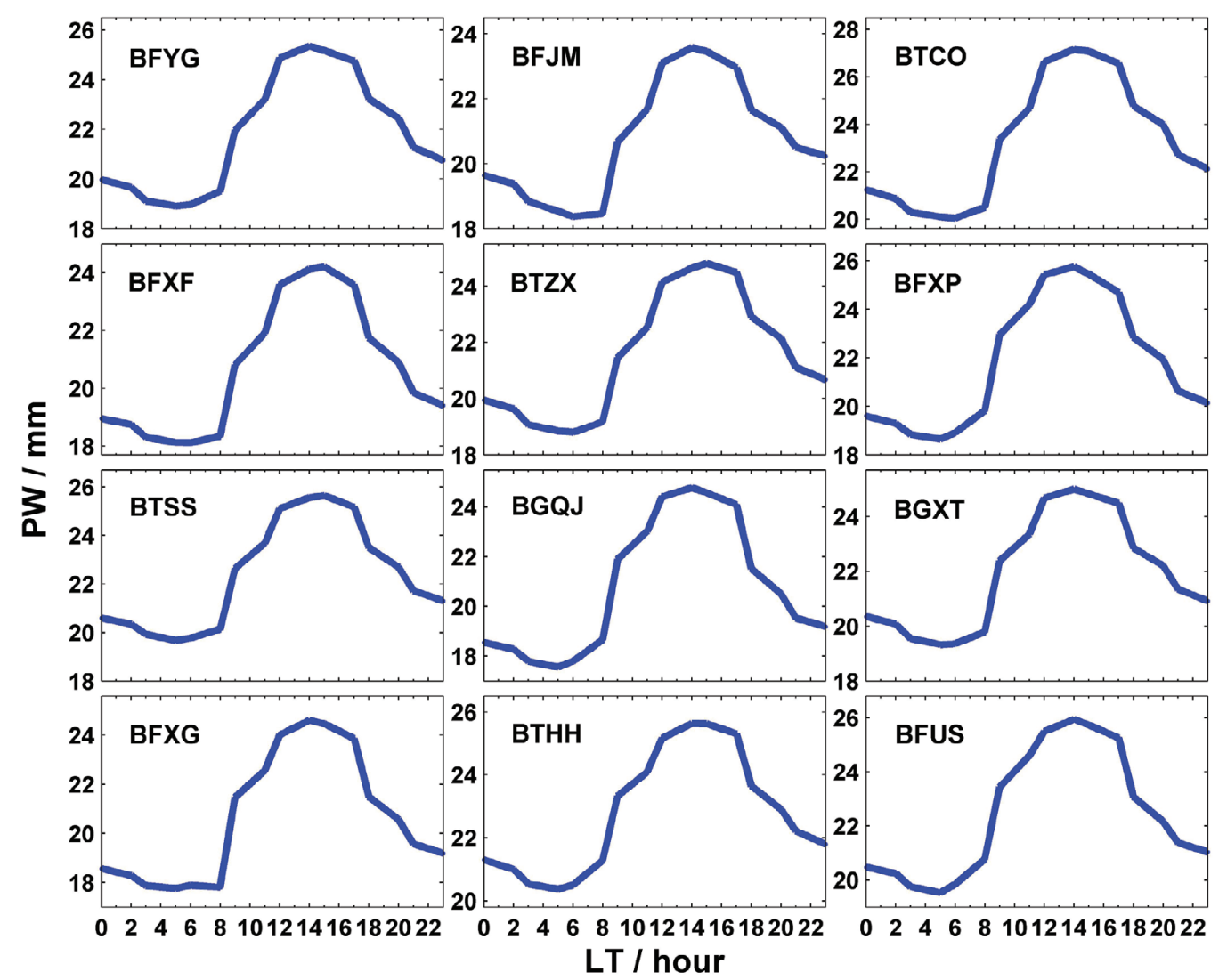

Fig. 5. Hourly mean PW over the Hubei stations in 2008.
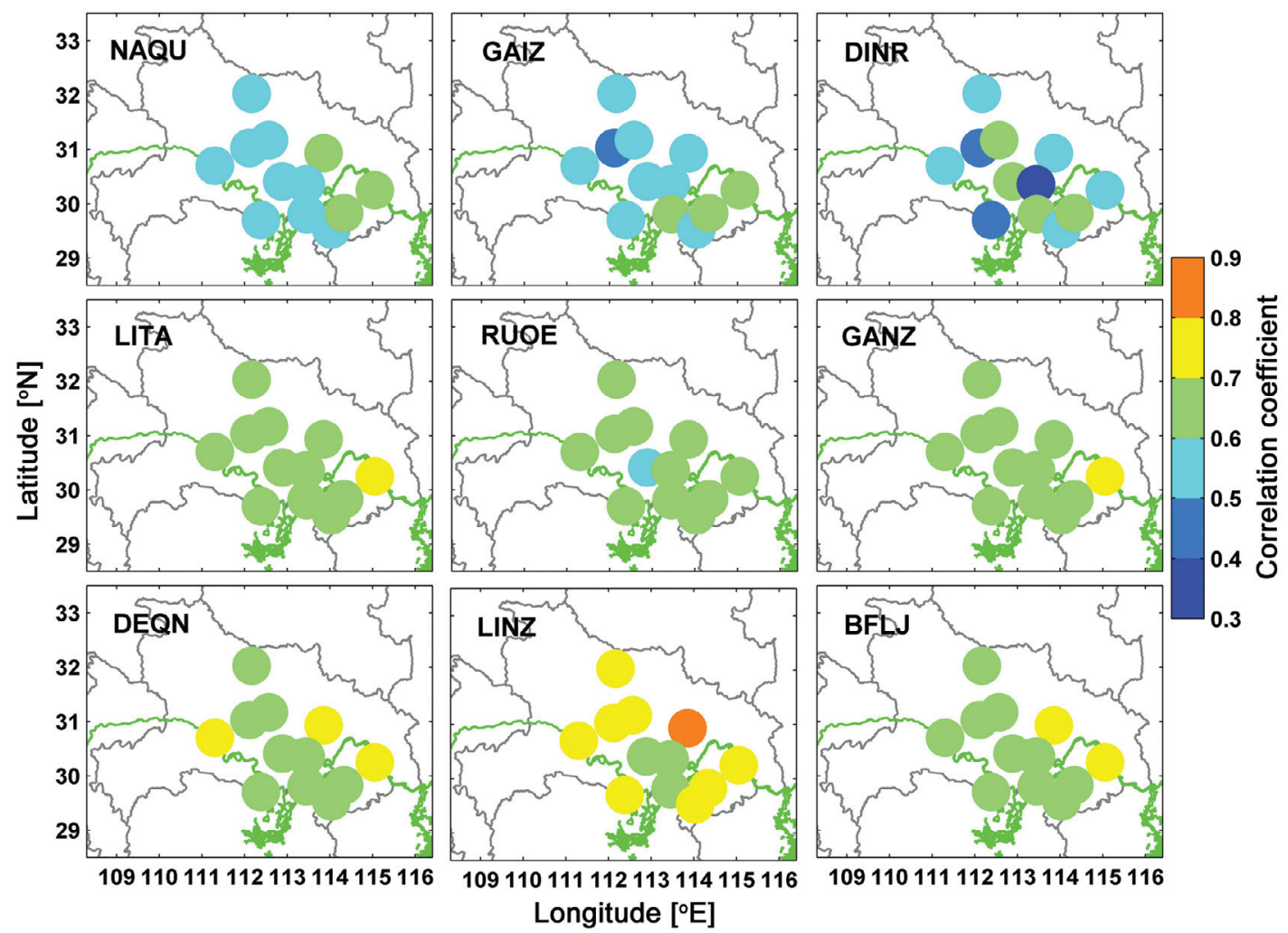

Longitude [ $\left.{ }^{\circ} \mathrm{E}\right]$

Fig. 6. Correlation coefficients for PW between the QTP and Hubei stations during the corresponding UT period. 
To better understand the correlation in PW between the QTP and Hubei stations, we consider all Hubei stations as a whole by averaging the $r_{P W}$ of these stations with a given one in the QTP, and use the mean $r_{P W}$ (marked as $r_{P W_{-} \text {mean }}$ ) as the correlation coefficient between the given QTP station and all the Hubei ones. Because the longitudinal distance between the QTP and Hubei is more than $1000 \mathrm{~km}$, many hours are required to transport air vapor from the QTP to Hubei. We calculate the $r_{P W_{-} \text {mean }}$ between each QTP station and all Hubei stations with a time lag from 0 to $168 \mathrm{~h}$ in Universal Time. The maximum $r_{P W_{-} \text {mean }}$ of each QTP station and its occurrence time are given in Table 2. Among the QTP stations, except DINR, the maximum $r_{P W_{-} \text {mean }}$ of the five eastern edge stations are close to the range 0.6924 - 0.7259, smaller than correlation for LINZ but larger than those of the two central QTP stations. In addition, the maximum $r_{P W_{-} \text {mean }}$ occurrence time is for the most distant station, and lowest for the eastern edge stations except DEQN and BFLJ. The positive correlation in PW between Hubei and the southern QTP edge and the eastern edge is more obvious than the central QTP.

$\mathrm{Xu}$ et al. (2002), Xu and Chen (2006) indicated that the QTP, especially the southern Plateau, and its eastern areas ("large triangle") are key areas for the transport of water vapor, which is important for initiating the rain and subsequent flooding in the Yangtze River during the Meiyu rainfall period (June to July). Our results show that there is a positive relationship in PW between the middle YRV and the QTP, especially the southern and eastern QTP. This may imply that the southern and eastern QTP are key regions for the atmospheric vapor being transported to the middle YRV. The results shown here are encouraging because it may be possible to find early warning signals in the atmospheric va-

Table 2. Maximum $r_{P W_{-} \text {mean }}$ between each QTP station and Hubei stations and the occurrence time with time lag of $0-168 \mathrm{~h}$ in UT.

\begin{tabular}{cccc}
\hline $\begin{array}{c}\text { QTP } \\
\text { station }\end{array}$ & $\begin{array}{c}\text { Longitude } \\
{\left[{ }^{\circ} \mathbf{E}\right]}\end{array}$ & $\begin{array}{c}\text { Max. } \\
\boldsymbol{r}_{P W_{-} \text {mean }}\end{array}$ & $\begin{array}{c}\text { Max. } \boldsymbol{r}_{P W_{\_} \text {mean }} \\
\text { occurrence time }[\mathbf{h}]\end{array}$ \\
\hline NAQU & 92.1 & 0.6331 & 50 \\
GAIZ & 84.1 & 0.6247 & 112 \\
DINR & 87.1 & 0.5961 & 47 \\
LITA & 100.3 & 0.6924 & 43 \\
RUOE & 103.0 & 0.7099 & 32 \\
GANZ & 100.0 & 0.7070 & 40 \\
DEQN & 98.9 & 0.7259 & 60 \\
LINZ & 94.4 & 0.7700 & 48 \\
BFLJ & 100.2 & 0.7047 & 61 \\
\hline
\end{tabular}

por of the QTP for identifying serious rainfall events in the middle YRV.

\section{CONCLUSIONS}

PW over the QTP and the middle YRV is analyzed. The results can be summarized as follows:

(1) The PW over the QTP has similar seasonal variation as the variation over the middle YRV, which is larger in summer than other months. Due to the barring effect of the QTP on the monsoon, the air is wetter in the southern Plateau and drier in the central area.

(2) Owing to the complex topography of the QTP, the diurnal variation of PW over the Plateau is more complex than the variation over the middle YRV with fluctuations occurring during the whole day. The minimum PW appears in the morning over both the QTP and the middle YRV; however, the peak over the QTP occurs during the night while that over the middle YRV occurs during the early afternoon.

(3) There is a positive correlation in PW between the middle YRV and the QTP, especially the southern and eastern edges of the QTP. This implies that the southern and eastern Plateau are key regions for transporting atmospheric vapor to the middle YRV, and it may be possible to find early warning signals in the atmospheric vapor of the QTP for identifying heavy rainfall events in the middle YRV.

Acknowledgements This research was supported by Heavy Rain Research Open Project of IHR, CMA (Grant No. IHR2007G01) and the social commonweal research program of Ministry of Science and Technology of the People's Republic of China (Grant No. GYHY201006009). The authors acknowledge the State Key Laboratory of Severe Weather, Chinese Academy of Meteorological Sciences for providing the GPS observations in Qinghai-Tibet Plateau of JICA database. Special thanks are given to Dr. Xinan Yue at University Corporation for Atmospheric Research (UCAR), Dr. Jiuhou Lei at University of Colorado, and Dr. Biqiang Zhao at the Institute of Geology and Geophysics of CAS for their efforts in greatly improving this paper.

\section{REFERENCES}

Bevis, M., S. Businger, T. A. Herring, C. Rocken, R. A. Anthes, and R. H. Ware, 1992: GPS meteorology: Remote sensing of atmospheric water vapor using the global positioning system. J. Geophys. Res., 97, 15787-15801, doi: 10.1029/92JD01517. [Link]

Bevis, M., S. Businger, S. Chiswell, T. A. Herring, R. A. Anthes, C. Rocken, and R. H. Ware, 1994: GPS meteorology: Mapping zenith wet delays onto precipitable water. J. Appl. Meteorol., 33, 379-386, doi: 10.1175/ 
1520-0450(1994)033<0379:GMMZWD>2.0.CO;2. [Link]

Davis, J. L., T. A. Herring, I. I. Shapiro, A. E. E. Rogers, and G. Elgered, 1985: Geodesy by radio interferometry: Effects of atmospheric modeling errors on estimates of baseline length. Radio Sci., 20, 1593-1607, doi: 10.1029/RS020i006p01593. [Link]

Elgered, G., J. L. Davis, T. A. Herring, and I. I. Shapiro, 1991: Geodesy by radio interferometry: Water vapor radiometry for estimation of the wet delay. J. Geophys. Res., 96, 6541-6555, doi: 10.1029/90JB00834. [Link]

Li, G. P., 2002: Dynamic Meteorology of the Tibetan Plateau, Meteorology Press, 251 pp. (in Chinese)

Liang, H., J. M. Liu, and S. K. Li, 2006: Analysis of precipitable water vapor source distribution and its seasonal variation characteristics over Tibetan Plateau and its surroundings. J. Nat. Resour., 21, 526-535. (in Chinese)

Peng, S. Q., X. D. Xu, X. H. Shi, D. X. Wang, Y. X. Zhu, and J. J. Pu, 2009: The early-warning effects of assimilation of the observations over the large-scale slope of the "World Roof" on its downstream weather forecasting. Chin. Sci. Bull., 54, 706-710, doi: 10.1007/s11434008-0560-6. [Link]

Qian, W. X., 2004: Synoptic Meteorology, Peking University Press, 267 pp. (in Chinese)
Shi, X., Y. Wang, and X. Xu, 2008: Effect of mesoscale topography over the Tibetan Plateau on summer precipitation in China: A regional model study. Geophys. Res. Lett., 35, L19707, doi: 10.1029/2008GL034740. [Link]

Xu, X. and L. Chen, 2006: Advances of the study on Tibetan Plateau experiment of atmospheric sciences. J. Appl. Meteorol. Sci., 17, 756-772. (in Chinese)

Xu, X., S. Tao, J. Wang, L. Chen, L. Zhou, and X. Wang, 2002: The relationship between water vapor transport features of Tibetan Plateau - monsoon "large triangle" affecting region and drought-flood abnormality of China. Acta Meteorol. Sin., 60, 257-266. (in Chinese)

Xu, X., R. Zhang, X. Shi, S. Zhang, L. Bian, X. Cheng, and G. Ding, T. Koike, C. Lu, and P. Li, 2008: A new integrated observational system over the Tibetan Plateau. Bull. Amer. Meteorol. Soc., 89, 1492-1496, doi: 10.1175/2008BAMS2557.1. [Link]

Yang, G. L., J. M. Liu, and J. T. Mao, 2002: Analysis on water vapor obtained with ground-based GPS over Tibetan area. Meteorol. Sci. Technol., 30, 266-272. (in Chinese)

Yu, S. H., W. L. Gao, and Q. Y. Gu, 2007: The middle-upper circulation analyses of the Plateau vortex moving out of Plateau and influencing flood in East China in recent years. Plateau Meteorol., 26, 466-475. (in Chinese) 